\title{
Da (bio) política às biopotências: reflexões sobre as condições atuais das políticas públicas de saúde mental no Brasil
}

\author{
Esmael Alves de Oliveira ${ }^{1}$ \\ Universidade Federal da Grande Dourados \\ Danilo Cleiton Lopes ${ }^{2}$ \\ Faculdade Anhanguera, Dourados
}

Resumo: O presente artigo apresenta algumas reflexões sobre as condições atuais das políticas públicas de saúde mental no Brasil. O cenário em que nos encontramos, no ano corrente, é de instabilidade em relação a algumas conquistas obtidas ao longo da história pelos trabalhadores e usuários desses serviços. Para fins de análise, e tomando como base as reflexões de Michel Foucault, debruçamo-nos tanto sobre a "Política do Ministério da Saúde para a atenção integral a usuários de álcool e outras drogas" quanto sobre a nota técnica n. 11/2019 intitulada "Nova Saúde Mental", da Coordenação-Geral de Saúde Mental, Álcool e Outras Drogas. A partir do estudo dessas duas materialidades biopolíticas esperamos evidenciar tanto os mecanismos produtores de "morte e/ou assujeitametos" quanto as diferentes estratégias de mobilização e resistências (biopotências). Desse modo, reverberamos as biopotências e resistências por novas superfícies de registro: por uma sociedade sem manicômios.

Palavras-chave: saúde mental; álcool e drogas; biopolítica; biopotência.

${ }^{1}$ Professor adjunto, do curso de Ciências Sociais, do Programa de Pós-Graduação em Antropologia (PPGAnt) da Faculdade de Ciências Humanas da Universidade Federal da Grande Dourados (FCH/UFGD) e do Programa de Pós-Graduação em Antropologia Social da Universidade Federal de Mato Grosso do Sul (PPGAS/UFMS). Doutor em Antropologia Social pela Universidade Federal de Santa Catarina (UFSC, 2014), com pós-doutorado junto ao Núcleo de Pesquisa em Antropologia do Corpo e da Saúde (NUPACS/UFRGS, 2018).

${ }^{2}$ Mestre em Psicologia pelo Programa de Pós-Graduação em Psicologia (PGPsi/UFGD) na linha de pesquisa de Processos Psicossociais (2018). Especialista em Saúde pela Residência Multiprofissional em Saúde na ênfase de Atenção à Saúde Indígena pelo Hospital Universitário da Universidade Federal da Grande Dourados (HU/UFGD, 2016). Graduado em Psicologia (Bacharelado e Licenciatura) pela Faculdade de Ciências Humanas da Universidade Federal da Grande Dourados (FCH/UFGD, 2013). 


\title{
From the (bio) politicies to biopotencies: \\ reflections on current conditions of public mental health policies in Brazil
}

\begin{abstract}
This article presents some reflections on the current conditions of the public mental health policies in Brazil. The scenario we are now facing, in the current year, shows instability regarding some achievements obtained throughout history by workers and users of those services. For the purpose of analysis and based on the reflections by Michel Foucault, we have focused closely on the "Policy of the Department of Health towards the integrated health care of users of alcohol and other drugs" regarding technical note n. 11/2019 whose title was "New Mental Health" by the General Coordination of Mental Health, Alcohol, and Other Drugs. Drawing from these two biopolitical materials we expect to evince both the mechanisms producing "death and/or submission of subjects" and the different strategies of mobilization and resistance (biopotentials). Thus, we reverberate the biopotentials and resistances by means of new surfaces of domain: looking forward to a society with asylums and madhouses.
\end{abstract}

Keywords: mental health; alcohol and drugs; biopolitics; biopotential.

\section{De la política (bio) a las biopotencias: reflexiones sobre las condiciones actuales de las políticas públicas de salud mental en Brasil}

\begin{abstract}
Resumen: El presente texto presenta algunas reflexiones sobre las actuales condiciones de las políticas públicas de salud mental en el Brasil. El escenario en que nos encontramos, en el corriente año, es de inestabilidad con relación a algunas conquistas obtenidas a lo largo de la historia por los trabajadores y usuarios de estos servicios. Para fines de análisis, y tomando como base las reflexiones de Michel Foucault, nos focalizamos tanto sobre la "Política del Ministerio de la Salud para la atención integral a los usuarios de alcohol y otras drogas" como también sobre la nota técnica n. 11/2019 titulada, "Nueva Salud Mental", de la Coordinación-General de Salud Mental, Alcohol y Otras Drogas. A partir de estas dos materialidades biopolíticas esperamos poner en evidencia tanto los mecanismos productores de "muerte y/o asujetamiento" cuanto a las diferentes estrategias de movilización y resistencias (biopotencias). De ese modo, reverberamos las biopotencias y resistencias por nuevas superficies de registro: por una sociedad sin manicomios.
\end{abstract}

Palabras clave: salud mental; alcohol y drogas; biopolítica; biopotência. 
"Repara bem no que não digo".

Paulo Leminski

"Cada um sabe a dor e a delícia de ser o que é".

Caetano Veloso

$\mathrm{O}$

presente artigo apresenta algumas reflexões sobre as condições atuais das políticas públicas de saúde mental no Brasil. O cenário em que nos encontramos, no ano corrente, é de instabilidade em relação a algumas conquistas obtidas ao longo da história pelos trabalhadores e usuários desses serviços. Entre essas conquistas democráticas, destacam-se os movimentos conhecidos como a Luta antimanicomial e a Reforma Psiquiátrica, finalmente consolidada legalmente pela lei n. 10.216, de 2001. Trata-se de dois movimentos fundamentais no processo de redemocratização do país, que se articulam e podem ser melhor compreendidos pelos trabalhos de Luchmann e Rodrigues (2007) e Tenório (2002).

As reflexões aqui apresentadas são compostas pela análise da "Política do Ministério da Saúde para a atenção integral a usuários de álcool e outras drogas" e da nota técnica n. 11/2019 intitulada "Nova Saúde Mental”, da Coordenação-Geral de Saúde Mental, Álcool e Outras Drogas; Departamento de Ações Programáticas Estratégicas e Secretaria de Atenção à Saúde e Ministério da Saúde (BRASIL, 2019). Esses documentos são articulados às vivências empíricas da Rede de Atenção Psicossocial (RAPS) por parte de um dos autores em um município do interior do Estado de Mato Grosso do Sul.

Nesse cenário, encontramo-nos por vezes na posição de trabalhadores de saúde e/ou de docentes universitários em espaços de produção de cuidados em saúde mental. Assim, para além da análise dos dispositivos legais já referidos, que compõe a primeira cena deste trabalho, será apresentado um episódio dessas vivências, dividido na segunda e terceira cena articuladas aos dispositivos legais, junto aos sujeitos usuários dos serviços, familiares, trabalhadores e gestores de saúde. Com isso, objetivamos pensar as materialidades discursivas que produzem o sujeito e a subjetividade "usuário de álcool e drogas" e "portador de transtorno mental": entre continuidade, descontinuidades e retrocessos.

Para isso, inspirando-nos nas reflexões de Michel Foucault sobre biopoder e biopolítica $(1988,2007)$, buscamos deslindar as práticas discursivas que normalizam as ações do Ministério da Saúde (MS), em documentos distintos, em torno de grupos socialmente vulneráveis e cujos estilos de vida tornam-se alvos de atenção e intervenção por parte de um estado que busca a todo custo "fazer viver e deixar morrer" (FOUCAULT, 1988).

Desse modo indagamos: seriam a política do MS e a nota técnica uma estratégia biopolítica? Quais as continuidades e descontinuidades dos jogos de saberpoder que forjam sujeitos e práticas? Face ao modelo biopolítico das políticas de 
saúde, haveria espaço para a produção de biopotências? São aspectos que buscaremos explorar.

\title{
Diante de um cenário (bio-micro)político
}

Produto de intensas mobilizações sociais, a política para a atenção integral a usuários de álcool e outras drogas só pode ser plenamente compreendida se associada a um contexto político-social mais amplo que se instaura no Brasil, sobretudo a partir da década de 1980, em torno de uma concepção de saúde integral e acaba por resultar na criação do SUS. Nos termos de Santos e Ferla,

\begin{abstract}
Na história do sistema de saúde brasileiro, um longo caminho foi percorrido para que o cuidado às pessoas que usam drogas fosse incorporado às políticas e endereçado aos serviços de saúde e, em especial, na principal porta de entrada do sistema, que são as unidades de atenção básica. A atenção aos cidadãos em uso dessas substâncias iniciase no princípio dos anos 1990, com a adoção de uma abordagem voltada para a Redução de Danos (RD), como no conjunto de ações de prevenção à AIDS e, posteriormente, em 2003, com a Política do Ministério da Saúde de Atenção Integral ao Usuário de Álcool e outras Drogas. (SANTOS e FERLA, 2017: 833)
\end{abstract}

Contudo, nem sempre foi assim. Vale lembrar que, ao longo de todo o século XX, no Brasil, predominou um modelo de intervenção junto a usuários de álcool e drogas de viés predominantemente jurídico-policialesco. Se em um primeiro momento o consumo de "drogas ilícitas" mostrava-se incipiente, o mesmo não pode ser afirmado do consumo de bebidas alcoólicas. De todo modo, havia uma tendência a serem estes considerados pelo viés punitivista e higienista. Tal compreensão esteve de acordo com os pactos acordados pelo Brasil em grandes convenções internacionais (como a convenção de Haia de 1911) e devidamente reiterados na esfera legal (por exemplo no Código Penal Brasileiro, de 1924) (MACHADO e MIRANDA, 2007: 803).

Conforme Machado e Miranda (2007), a partir da década de 1970, entra em cena outro ator importante: a medicina. Essa "entrada" implicaria a passagem de um problema de segurança pública para uma questão de saúde pública, pela qual o usuário oscilaria entre a tipificação de "delinquente" à de "doente" (MACHADO e MIRANDA, 2007: 804). Mais uma vez, os aparatos de governamentalidade encontram, para além do campo jurídico, na medicina/psiquiatria, uma das bases de sustentação para o enquadramento de sua população. Nesses termos, o uso e a dependência de drogas passam a ser compreendidos pelo viés da medicalização. Eis que surge a figura do "dependente químico".

Nesse governo da vida, outras estratégias foram constituídas tais como: a criação do Conselho Federal de Entorpecentes (Confen) na década de 1980 (extinto em 1998), o Programa de Ação Nacional Antidrogas (de 1996), o Sistema Nacional Antidrogas (SISNAD, de 1998) e seus futuros desdobramentos, como a política que estamos analisando (BRASIL, MS, 2003). Além disso, cabe mencionar o importante marco do $1^{\circ}$ Fórum Nacional Antidrogas, ocorrido em 1998, que resultou na Política Nacional Antidrogas (PNAD, de 2001), e o $2^{\circ}$ Fórum Nacional Antidrogas, realizado no mesmo ano. Observam-se, em todas essas iniciativas tensões, embates, negociações, impasses, retrocessos, mas também avanços. Não se pode ignorar, contudo, que todas essas mobilizações, a partir da década de 1990, foram fundamentais para uma mudança de pauta: por uma atuação norteada pela redução de danos e não pela repressão, até então explícita na "política de abstinência".

Como toda política pública, os documentos que servem de base às ações em saúde também precisam ser analisados à luz não apenas de seus dilemas e limites, 
mas também, e principalmente, de suas possibilidades (BRIGAGÃO, NASCIMENTO e SPINK, 2011).

Como bem pontuado por Guatarri, em "Revolução Molecular":

\begin{abstract}
Assim como me parece ilusório apostar numa transformação paulatina da sociedade, penso que as tentativas microscópicas, do tipo comunidades, comissões de bairro, a organização de uma creche numa faculdade etc., podem desempenhar um papel absolutamente fundamental. E trabalhando em pequenas tentativas como estas que se contribui para o desencadeamento de grandes fraturas [...]. Neste campo, acredito num reformismo permanente da organização revolucionária. Mais valem dez fracassos repetidos ou resultados insignificantes que uma passividade embrutecida face aos mecanismos de recuperação e as manipulações burocráticas dos militantes profissionais. (GUATARRI, 1985: 85)
\end{abstract}

Assim, como algo que é produzido em determinado tempo sócio-históricopolítico, atravessado por valores e ideologias e mobilizado por diferentes interesses e demandas, há que se pensar não apenas a dimensão institucional das normativas (nível macro), mas também os agentes que lhe dão contorno, os termos e categorias que constroem os sentidos - responsáveis por dizer determinada coisa e não outra - e ao mesmo tempo aquilo que escapa às intenções de seus formuladores (nível micro).

Conforme nos explica Foucault, o poder deve ser entendido como:

\begin{abstract}
multiplicidade de correlações de forças imanentes ao domínio onde se exercem e constitutivas de sua organização; o jogo que, através de lutas e afrontamentos incessantes as transforma, reforça, inverte; os apoios que tais correlações de força encontram umas nas outras, formando cadeias ou sistemas ou ao contrário, as defasagens e contradições que as isolam entre si; enfim, as estratégias em que se originam e cujo esboço geral ou cristalização institucional toma corpo nos aparelhos estatais, na formulação da lei, nas hegemonias sociais. (FOUCAULT, 1988: 88-89)
\end{abstract}

Há que se estar atento às fissuras, às ambiguidades, às contradições, às complexas redes de negociação e aos agenciamentos que atravessam as políticas e que produzem resistência. Afinal, o poder "não é uma instituição e nem uma estrutura, não é uma certa potência de que alguns sejam dotados: é o nome dado a uma certa situação estratégica complexa numa sociedade determinada" (FOUCAULT, 1988: 89).

Isso permite distanciarmo-nos tanto de uma leitura que resvale em uma defesa/adesão cega, impossibilitando inclusive avanços, quanto de uma crítica que implique a completa desqualificação do que foi construído e consolidado. Desse modo, considerar os atravessamentos de saber-poder que constituem as práticas e perceber também os micropoderes, agenciamentos e resistências que são gestados em seu interior (junto e ao mesmo tempo) nos possibilita uma análise mais amadurecida das políticas públicas (e, neste caso, de saúde). É preciso, portanto, refletir tanto quanto sobre a dimensão político-institucional, sobre as linhas de fuga, os entre-lugares, as ambiguidades que atravessam espaços, instituições, burocracias e relações e que revelam que as tentativas de captura unilateral dos mecanismos de controle/poder são precárias e, nesse sentido, nunca plenamente realizadas.

Torna-se imperioso, assim, fugirmos das leituras fatalistas e vitimizadoras.

Partir, se evadir, é traçar uma linha. [...] A linha de fuga é uma desterritorialização. Os franceses não sabem bem o que é isso. É claro que eles fogem como todo mundo, mas eles pensam que fugir é sair do mundo, místico ou arte, ou então alguma coisa covarde, porque se escapa dos engajamentos e das responsabilidades. Fugir não é renunciar às ações, nada mais ativo que uma fuga. É o contrário do imaginário. É também fazer fugir, não necessariamente os outros, mas fazer alguma coisa fugir, fazer um sistema vazar como se fura um cano. [...]. Fugir é traçar uma linha, linhas, toda uma cartografia. Só se descobre mundos através de uma longa fuga quebrada. (DELEUZE, 1998: 49) 
Portanto, o que as entrelinhas das políticas promovidas pelo Ministério da Saúde (2003, 2019) em relação a saúde mental nos dizem tanto em termos dessas linhas de fuga quanto das tentativas biopolíticas para capturá-las?

No que tange especificamente à "Política do Ministério da Saúde para atenção integral a usuários de álcool e outras drogas”, há vários aspectos importantes e que avançam no sentido de uma compreensão mais ampla do fenômeno da dependência química e que se revelam em um compromisso com a transversalização, com a ruptura com as compreensões e lógicas binarizantes e estigmatizantes, no enfoque na redução de danos (como método e estratégia) e não na abstinência, em uma preocupação com uma abordagem clínico-política, na atenção na construção de redes de suporte social, na perspectiva ampliada da clínica e de saúde pública, em uma pauta preventiva, pelo foco na educação e no controle social. (BRASIL, 2003)

Nos termos de Machado e Miranda,

Trata-se de um marco teórico-político que rompe com abordagens reducionistas e considera a presença das drogas nas sociedades contemporâneas como um fenômeno complexo, com implicações sociais, psicológicas, econômicas e políticas; e que, portanto, não pode ser objeto apenas das intervenções psiquiátricas e jurídicas - como ocorreu historicamente no Brasil - nem tampouco de ações exclusivas da saúde pública. (MACHADO; MIRANDA, 2007: 818)

Apesar disso, em um movimento de analisar tal política com certo distanciamento, há que se pensar também suas ambiguidades e impasses. Quais os avanços implicariam necessariamente a permanência de contradições? E o que dizer dos atuais retrocessos em voga? São questões que buscaremos problematizar a partir de diferentes cenas.

\section{A política de álcool e outras drogas: entre descontinuidades e continuidades}

Segundo Michel Foucault (1988), na passagem do século XVII para o século XVIII, vislumbra-se uma mudança paradigmática nos regimes de saber-poder. Se até então o poder soberano era aquele a quem "o direito de causar a morte ou de deixar viver" (FOUCAULT, 1988: 128) se impunha, transformações de ordem histórica, social, econômica e política possibilitarão que, ao longo do século XVIII (denominado pelo autor de época clássica), constitua-se um novo modelo de soberania em que o paradigma da morte cede lugar ao da "vida".

Há, para o autor, assim, a emergência de um poder que se produz e se movimenta em duas grandes direções: uma individual e outra coletiva. Na perspectiva foucaultiana, o primeiro movimento seria centrado no corpo-máquina, cujo foco deveria ser o adestramento, a ampliação das aptidões, a subtração das forças e a produção de um corpo dócil e útil, a ser forjado e integrado por meio de uma anátomo-política do corpo humano que tinha na disciplina seu dispositivo por excelência (FOUCAULT, 1988).

O segundo movimento, configurado a partir da segunda metade do século XVIII, teria como foco o corpo-espécie, pelo qual os processos biológicos, o controle da população, dos nascimentos, da mortalidade, do nível de saúde, da duração da vida e da longevidade ganhariam a primeira cena e constituiriam uma biopolítica da população (FOUCAULT, 1988: 31). Assim, seria a incidência da dis- 
ciplina sobre a dimensão anatômica (corpo) e da regulamentação sobre a dimensão biológica (espécie), que inauguraria a era do biopoder (FOUCAULT, 1988: 132). Nesse cenário biopolítico, a polícia e a estatística aparecem como mecanismos indispensáveis para os procedimentos de governo cujo foco passa a ser a população.

Segundo Foucault (2007), podemos inferir, pois, que vivemos na era da governamentalidade, esta compreendida como:

\begin{abstract}
1) o conjunto constituído pelas instituições, procedimentos, análises e reflexões, cálculos e táticas que permitem exercer esta forma bastante específica e complexa de poder, que tem por alvo a população, por forma principal de saber a economia política e por instrumentos técnicos essenciais os dispositivos de segurança; 2) a tendência que em todo Ocidente conduziu incessantemente, durante muito tempo, à preeminência deste tipo de poder, que se pode chamar de governo, sobre todos os outros - soberania, disciplina etc. - e levou ao desenvolvimento de uma série de aparelhos específicos de governo e de um conjunto de saberes; 3) o resultado do processo através do qual o Estado de justiça da Idade Média, que se tornou nos séculos XV e XVI Estado administrativo, foi pouco a pouco governamentalizado. (FOUCAULT, 2007: 291-292)
\end{abstract}

O que isso nos ajuda a pensar com relação à política de álcool e drogas? Voltemos ao documento:

O enfrentamento desta problemática constitui uma demanda mundial: de acordo com a Organização Mundial de Saúde, cerca de 10\% das populações dos centros urbanos de todo o mundo, consomem abusivamente substâncias psicoativas, independentemente da idade, sexo, nível de instrução e poder aquisitivo. (BRASIL, 2003: 5-12)

E continua:

[...] dados fornecidos por estudo capitaneado pela Universidade de Harvard indicam que, das dez doenças mais incapacitantes em todo o mundo, cinco são de origem psiquiátrica: depressão, transtorno afetivo bipolar, alcoolismo, esquizofrenia e transtorno obsessivo-compulsivo (Murray e Lopez, 1996). (BRASIL, 2003: 12)

Observa-se que um dos aspectos presentes nos trechos é justamente a centralidade que os dados estatísticos ocupam. É a estatística, conforme Foucault (2007), que vai revelar as características próprias da população, apontar o número de mortos, de doentes, regularidade de acidentes, etc. A estatística rimaria com as táticas da governamentalização, pois,

\begin{abstract}
se a estatística tinha até então funcionado no interior do quadro administrativo da soberania, ela vai revelar pouco a pouco que a população tem uma regularidade própria: número de mortos, de doentes, regularidade de acidentes, etc.; a estatística revela também que a população tem características próprias e que seus fenômenos são irredutíveis aos da família: as grandes epidemias, a mortalidade endêmica, a espiral do trabalho e da riqueza, etc.; revela finalmente que a população através de seus deslocamentos, de sua atividade, a população produz efeitos econômicos específicos. (FOUCAULT, 2007: 288)
\end{abstract}

Nesse sentido, ela serve para "atestar", "garantir", "respaldar", "justificar" uma dada intervenção. No caso específico da política de álcool e drogas, torna-se um "problema" que merece a atenção de organismos governamentais e não governamentais, uma vez que estes estão inseridos num discurso do numericamente justificável. Assim, faz-se necessário o uso de:

Campanhas, através das quais se age diretamente sobre a população, e técnicas que vão agir indiretamente sobre ela e que permitirão aumentar, sem que as pessoas se deem conta, a taxa de natalidade, ou dirigir para uma determinada região ou para uma determinada atividade os fluxos da população. (FOUCAULT, 2007: 289)

Além disso, conforme já pontuado por outros autores (BARROSO, KNAUTH e MACHADO, 2014; RUI, 2014), não é incomum o discurso moral se apresentar 
como um dos elementos constituintes da política oficial de saúde, sobretudo no que diz respeito ao modo como as intervenções são realizadas na prática. É assim que, sem dificuldades, encontramos frases ou categorias que denotam noções de desvio, de risco, de sofrimento. Instaura-se um verdadeiro pânico moral, cujo objetivo é a comoção social em torno do diferente e dissonante tido como algo perigoso, abjeto, anormal, patológico e que está presente em noções como: "sofrimento global trazido por este consumo", "aqueles que sofrem devido ao consumo de álcool e drogas" (BRASIL, 2003: 5). Como em um jogo de figura e fundo, de afirmação da vida em nome da morte, constrói-se um posto simétrico rousseauniano: "a promoção de maior qualidade de vida" (BRASIL, 2003: 5). Mas o que é qualidade de vida? Segundo quais critérios? Para quem? Como pensá-la sem considerarmos as condições objetivas da vida? Enfim, seria tal política apenas mais uma estratégia biopolítica?

Sem desconsiderar que se trata de um plano datado de $2003 \mathrm{e}$, portanto, marcado por um determinado contexto e por um conjunto de preocupações localizadas no tempo, há que se pensar como, por meio da materialidade de seu discurso, a ação ecoa para além da marcação temporal. Haveria no Plano, de fato, uma completa "superação" dos modelos jurídico-policialescos e biomédicos que o antecederam? Afinal, não podemos ignorar que,

Orientada por um novo norte - a redução dos riscos e danos - a política de saúde para usuários de drogas, estabelecida em 2003, não deixa de ter como alguns de seus antecedentes as práticas, os serviços e as condições propiciadas e apoiadas pelo aparato jurídico institucional repressivo. (MACHADO e MIRANDA, 2007: 819)

Assim, é no mínimo ambígua a exposição de um discurso que se pretende de "reconhecimento", mas que ao mesmo tempo reitera uma lógica de "superação do consumo" (BRASIL, 2003: 8). Logo, a dependência acaba por aparecer como um risco em si mesmo, como algo a ser enfrentado, combatido, eliminado a qualquer custo. O discurso-estratégia do pânico ganha a primeira cena e a relação entre juventude e álcool lhe é acoplada de modo determinístico e inescapável, cujo resultado só poderia ser catastrófico e que se revelaria em "altos índices de abandono escolar, bem como [n]o rompimento de outros laços sociais" (BRASIL, 2003: 13). Dessa forma, não surpreende o estabelecimento de uma relação determinista "entre o uso do álcool, outras drogas e os eventos acidentais ou situações de violência” (BRASIL, 2003: 14).

E o que pensar sobre o fato de que, ao longo do Plano, a dependência resvala em uma compreensão diagnóstica (portanto biomédica), por meio da qual as razões para uma possível dependência seriam devidamente compreendidas na chave dos diagnósticos, dos distúrbios, dos transtornos, apelando quase para uma dimensão hereditária (BRASIL, 2003: 13)?

Além disso, seria o consumo de "drogas ilícitas" o único problema de saúde pública na área de saúde mental no Brasil? Ainda que o plano reconheça o aumento do número crescente de consumo de psicofármacos (BRASIL, 2003: 14), não nos parece que esta seja uma questão de primeira ordem. Isso porque, em comparação ao uso do álcool e de drogas ilícitas, o consumo de psicofármacos legalizados parece ser secundarizado na análise.

Desse modo, como desconsiderar o modelo social vigente que privilegia homens e mulheres produtivos e bem-sucedidos? É a estes referentes (produtividade e sucesso) que é comparado e contrastado o público alvo das políticas oficiais de saúde? Ou seja, tornam-se um problema quando deixam de atingir certa expectativa socialmente convencionalizada de comportamento esperado? Esta- 
riam os workaholics ${ }^{3}$, assíduos consumidores de psicoestimulantes e antidepressivos, mas socialmente hiperprodutivos, também contemplados pelas políticas de saúde? Estariam eles devidamente representados na categorização "outras drogas"? Ou seu produtivismo dispensaria qualquer atenção e preocupação por parte dos organismos de saúde? Conforme apontam Machado e Miranda (2007: 806), há uma

\begin{abstract}
tendência observada no Brasil de estabelecer ações governamentais tendo em vista os compromissos assumidos no plano internacional para controlar e reprimir o uso de drogas ilícitas, e não orientadas pelas necessidades de atenção surgidas com o consumo de substâncias psicoativas.
\end{abstract}

Outra questão importante do Plano e que permanece pouco esclarecida é quanto a uma possível articulação entre justiça, segurança e defesa (BRASIL, 2003: 9). Em quais termos? Em um cenário como o nosso, intensamente marcado pelo encarceramento em massa 4 , pela violência policial, pela criminalização de minorias sociais e raciais (pobres e negros), qual seria o papel da segurança e da defesa? Essa parceria se daria em quais termos? Respeitaria quais limites?

Tais questões, por mais complexas que sejam, precisam ser encaradas a fim de problematizarmos os dispositivos ideológicos que produzem e reiteram desigualdades (ainda quando seu propósito se pretende outro) e que retroalimentam e sustentam exclusões sociais baseadas em marcadores sociais de diferença (raça/etnia, classe, gênero, geração). Afinal, a quem se deve "fazer viver e deixar morrer"? Que vidas são biopoliticamente importantes? Por quê? Para qual(is) propósito(s)? A partir de quais condições?

Há que se analisar como as táticas de governo têm gerido vidas precárias e precarizadas. Nesse sentido, importa saber como os atuais discursos de saúde, cuidado e qualidade de vida têm servido como táticas eficazes de domínio de um Outro socialmente indesejável, com a finalidade de dizer a ele como deve ser, como deve viver, como deve se comportar, enfim, como deve morrer.

Compreender a arte de governar sob a perspectiva de Foucault (2007) significa estarmos atentos a instituições, procedimentos, análises e reflexões, cálculos e táticas de saber e de poder que cercam o governo das populações, tendo em vista que:

Gerir a população significa geri-la em profundidade, minuciosamente, no detalhe. A ideia de um novo governo da população torna ainda mais agudo o problema do fundamento da soberania e ainda mais aguda a necessidade de desenvolver a disciplina. Devemos compreender as coisas não em termos de substituição de uma sociedade de soberania por uma sociedade disciplinar e desta por uma sociedade de governo. Trata-se de um triângulo: soberania-disciplina-gestão governamental, que tem a população como seu alvo principal e os dispositivos de segurança como seus mecanismos essenciais. (FOUCAULT, 2007: 291)

3 Termo utilizado para se referir a pessoas altamente produtivas e que trabalham compulsivamente.

4 Diversos trabalhos e dados apontam que o Brasil está entre os países que mais prende no mundo (Cf. Rafael GODOI, 2015; Jacson BELUZI, 2019). 


\section{"Havia um retrocesso no meio do caminho"s: Nota técnica no 11/2019 e seus (inter)ditos}

Em 1987, quando ocorre em Bauru (SP) a I Conferência Nacional de Saúde Mental e o II Congresso do Movimento dos Trabalhadores de Saúde Mental, que contam com a presença de novos atores, como é o caso das associações de usuários dos serviços e familiares, destaca-se a busca pela transformação das práticas psiquiátricas. Deflagra-se, com isso, uma renovação teórica e política na atenção à saúde mental, com a "afirmação do laço social entre os profissionais e a sociedade" no enfrentamento dos desafios daí oriundos. Com a participação de usuários e familiares, é criada uma espécie de documento oficial: o Manifesto de Bauru, que dá origem à Articulação Nacional do Movimento da Luta Antimanicomial (LUCHMANN e RODRIGUES, 2007: 403).

Desde então, em grande parte do território nacional, é realizada anualmente a semana da Luta Antimanicomial. O mesmo ocorre atualmente nas territorialidades onde atuamos na produção de sentidos e cuidados em saúde mental. Nessas territorialidades ocorreu, ao longo de 2019, junto à RAPS do município de Dourados (MS), uma "Oficina da Luta antimanicomial”. Estavam presentes usuários (as), gestores (as) e trabalhadores (as) de saúde mental, psicólogos (as), enfermeiros (as), médicos (as) psiquiatras, assistentes sociais, entre outros (as). Esses atores-sujeitos representavam o Centro de Atenção Psicossocial (CAPS II), Centro de Atenção Psicossocial - Álcool e outras Drogas (CAPS ad), o Ambulatório de Saúde Mental e a Policlínica de Atendimento Infantil (PAI). Além deles, outros profissionais de saúde mental, atualmente na condição de docentes das universidades públicas e privadas no município em que funciona a RAPS e da capital do estado do Mato Grosso do Sul, fizeram parte dos diálogos como facilitadores, a convite da organização do evento.

Além da motivação intrínseca desde a deflagração do movimento da Luta antimanicomial, sinteticamente apresentado acima, o evento foi pensado tendo em vista as ameaças de retrocessos sinalizados pela nota técnica n. 11/2019 divulgada em 4 de fevereiro de 2019 no site do Ministério da Saúde (BRASIL, 2019). Ela foi retirada, em seguida, após a sinalização do descabimento da proposta, por parte dos conselhos federais e regionais das diferentes profissões de saúde e parte da sociedade civil, engajada na ressignificação das práticas e sentidos da saúde mental.

O evento se iniciou com a apresentação dos atores-sujeitos presentes que estavam sentados em roda. Ficou combinado que, inicialmente, cada facilitador traria algum tema disparador para que todos se articulassem entre si, com o objetivo de orientar os diálogos e discussões durante a oficina. Primeiramente, foi apresentada uma retrospectiva histórica do Movimento da Luta Antimanicomial e da Reforma Psiquiátrica, a partir da experiência de uma das profissionais-professoras $^{6}$ de saúde mental e saúde coletiva.

A narrativa seguinte versava sobre a nota técnica n. 11/2019 (BRASIL, 2019) e sobre os perigos que ela representa para o cuidado em saúde mental. O profissional-professor da área trazia alguns exemplos cotidianos de sua experiência an-

5 Aqui nos inspiramos no famoso poema "No Meio do Caminho" de Carlos Drummond de Andrade para pensarmos as dificuldades e entraves presentes na consolidação da política de saúde mental.

${ }^{6} \mathrm{O}$ termo profissional-professor está empregado dessa forma tendo em vista a fragmentação existente entre profissionais de saúde e professores, como herança maniqueísta da lógica aristotélica e método cartesiano, pelos quais não pode coabitar no mesmo sujeito funções diferentes, mesmo que sejam indissociáveis do ponto de vista vivencial. 
terior aos efeitos da Reforma Psiquiátrica e a sua formação profissional. Ponderou acerca dos avanços obtidos a partir do Movimento da Luta Antimanicomial e da diferença significativa que isso fez na sua formação profissional. Em sua fala se explicitava uma produção de subjetividade comprometida com a ruptura com o modelo hospitalocêntrico e asilar de controle dos ditos "doentes mentais" e "dependentes químicos", atualmente denominados pelas políticas públicas do Ministério da Saúde como "usuários de álcool e outras drogas" e "portadores de transtorno mental" (BRASIL, 2003; BRASIL, 2001).

A enunciação de abertura do facilitador tratava de alguns temas principais discutidos nacionalmente por inúmeras entidades profissionais, como o Conselho Federal de Psicologia - que, naquele momento, já havia se manifestado por meio de nota de repúdio ${ }^{7}$ - sobre a proposta governamental denominada "Nova Saúde Mental", a saber: inclusão de hospitais psiquiátricos nas Redes de Atenção Psicossocial (Raps); incentivo ao uso da eletroconvulsoterapia (ECT); internação de crianças e adolescentes; e o uso da abstinência no tratamento contra as drogas.

Sobre a "inclusão de hospitais psiquiátricos nas Raps", destacava o facilitador: "configura-se como um ataque às estratégias de desinstitucionalização dos grupos-sujeitos e da busca por sua autonomia nos processos de cuidado no território". Ainda segundo ele,

a institucionalização exclui o sujeito do convívio social e despotencializa o cuidado, potencializando apenas o controle dos corpos-mentes tal como era feito antes da Reforma Psiquiátrica. Então essa não é uma "Nova Saúde Mental", mas sim uma "contrarreforma”, isto é, contraria a Reforma Psiquiátrica e o próprio Movimento da Luta Antimanicomial. (Transcrição elaborada a partir da memória de um dos autores)

Ao tentar iniciar suas colocações sobre os riscos do incentivo ao uso da eletroconvulsoterapia (ECT), o profissional é imediatamente interrompido por um participante médico psiquiatra. Com um discurso fechado e volumoso, este se levanta e assevera: "Aí vocês estão me provocando. Vocês vêm da universidade, quando é assim nunca nem entraram no serviço e ficam falando isso. A eletroconvulsoterapia é um procedimento reconhecido cientificamente, não tem nada de choque como antigamente". No meio dessa fala houve a tentativa de aplauso por parte de uma participante, que dizia: "isso mesmo, doutor!", mas que se viu frustrada por não ter sido acompanhada pelos demais.

Preocupada com o tom da argumentação do ator-sujeito médico psiquiatra, uma das organizadoras da atividade questiona se não é possível para este participante aguardar o final da fala do facilitador e dos (as) demais para que possa ter seu momento de fala, assim como havia sido combinado coletivamente no início da oficina. O ator-sujeito dispara: "eu não posso falar? Eu vou falar sim". A organizadora então reafirma: "todos podem falar, só pedimos que aguarde o término da fala do professor". Irritado o médico psiquiatra conclui: "Então ‘tá’ bom, vou ficar aqui então", sentando-se ao lado do facilitador.

Ao perceber a fala e ação intimidatória do médico (M), o facilitador (F) se dirige a ele e o questiona: "você quer interditar minha fala? Porque não espera que conclua minha fala? Todos têm seu momento de falar”.

M. insiste: o que você está falando não existe, está falando o que não sabe.

F.: O que eu não sei?

M.: O que você falou sobre a eletroconvulsoterapia...

F.: Falei o quê? Você não me deixou concluir, já me interrompeu. Nem sabe o que vou dizer.

7 Disponível em: https://site.cfp.org.br/cfp-manifesta-repudio-a-nota-tecnica-nova-saude-mental-publicada-pelo-ministerio-da-saude/. Acesso em: 01 de agosto de 2019. 
M.: Então tá bom! - Levanta-se, joga um copo plástico no chão e se retira acompanhado de um psicólogo.

Ainda em um clima de perplexidade por parte de alguns participantes, uma médica psiquiatra afirma: "eu falo que não dá para colocar psiquiatra e psicólogo juntos". "Gente, não se pode querer proibir a ECT, é reconhecida”. A coordenadora do evento se desculpa pelo ocorrido, pede a compreensão dos demais em relação ao colega trabalhador de saúde mental, que se encontra na posição de médico psiquiatra, e sugere que a fala interrompida seja retomada.

Aparece nessa cena a articulação das três formas de objetivação do sujeito estudadas ao longo da obra de Foucault (1995). A primeira é o modo de investigação ou dito científico. Ademais, podem-se destacar ao menos três formas do modo de objetivação investigação-ciência: o sujeito do discurso instituído na filologia e na linguística; o sujeito produtivo trabalhador tramado pela análise das riquezas e economia; e o sujeito vivo, pensado pela biologia e pela história natural: o que emerge na fala do ator-sujeito médico psiquiatra que se vê atacado e provocado em sua intimidade. Ele se vê como o único sujeito produtivo trabalhador, pois, para ele, os demais nem sabem o que acontece em um serviço. Além disso, trata-se do sujeito do suposto saber-poder, que garante essa primeira forma de objetivação: o sujeito vivo do ponto de vista biológico.

O segundo modo de objetivação é chamado por Foucault (1995) de prática divisora, em que o sujeito é separado internamente e em relação aos outros. As principais objetivações são: "o louco e o são, o doente e o sadio, os criminosos e os bons meninos" (FOUCAULT, 1995: 231). No trabalho em saúde mental, segundo o registro de nossa vivência e análise, essa divisão se dá entre o sujeito médico e os demais trabalhadores de saúde, isto é, aquele que sabe e os demais "não sabedores". Destaca-se que ambos não podem coabitar sem que haja uma subalternização de um sobre o outro.

O terceiro modo de objetivação pode ser entendido como subjetivação, já que versa sobre a passagem do ser humano à própria condição de sujeito. Um exemplo disso é como, a partir do domínio da sexualidade, Foucault identifica por que os seres humanos aprendem a se reconhecer e a se identificar como sujeitos de sexualidade. No caso em análise, os indivíduos usuários do serviço de saúde mental são subjetivados como sujeitos do saber biomédico em detrimento de sua biopotência. Isto é, não nos importa o sujeito das relações humanas, dos afetos, das condições de vida e afins, reduzimo-lo ao corpo fisiológico e a suas alterações, desconectando-o assim da multiplicidade de atravessamentos vivenciados, seja do ponto de vista político, histórico, econômico, social e cultural, seja no âmbito singular, psíquico, existencial, que, de modo geral, antecedem suas alterações neuroquímicas.

Partindo dessa perspectiva, a técnica biomédica da ECT mostra-se como um instrumento à disposição para se concertar o sujeito biológico mecanicista defeituoso, visto por esse prisma unilateral de subjetivação.

De volta à cena, o professor-profissional de saúde mental retoma sua argumentação sinalizando que não gostaria de que as coisas tomassem tal rumo. Contudo, não poderia ser interditado como um "doente mental" no período manicomial e ter sua fala deslegitimada pela suposta autoridade científica, neste caso representada pelo profissional psiquiatra: 
Sinaliza com isso que o fato de estar na condição de professor não o diminui em relação aos demais, tampouco o torna melhor por isso. Portanto, caso as pessoas que estivessem ali concordassem com a afirmativa que deslegitima a fala de um sujeito por pertencer à universidade, ele não faria questão de continuar sua fala. É prontamente acolhido e solicitam a continuidade de suas contribuições.

Em seguida, retoma seu discurso do ponto de onde havia sido interrompido e continua sua análise em relação ao incentivo ao uso da eletroconvulsoterapia (ECT):

\begin{abstract}
É preciso observar o que está sendo analisado. Em nenhum momento falei (até porque fui interrompido) de proibir ou deslegitimei o valor terapêutico da eletroconvulsoterapia, ou de qualquer outra técnica, até porque ela já é autorizada e utilizada atualmente. A crítica está no incentivo dessa prática. Ela deve ser utilizada em casos muito específicos, com critérios muito bem estabelecidos e respeitados, e não ser incentivada, pois será posta em relações de poder, das quais, historicamente, como estamos apontando, reproduzem o controle e não o cuidado.
\end{abstract}

Nesse ponto, o ator-sujeito em questão converge na implicação junto às lutas antiautoritárias e à resistência tal como assinaladas por Foucault (1995: 235): "O que é questionado é a maneira pela qual o saber circula e funciona, suas relações com o poder. Em resumo, o régime du savoir".

Em seguida, aponta que o sujeito usuário dos serviços de saúde mental, seja "usuário de álcool ou outras drogas" ou "acometido por transtorno mental", deve ser acolhido para o cuidado e incluído nesse processo, não de forma vertical ou horizontal, mas de maneira transversal na busca de sua autonomia. Isso implica não uma obediência inflexível ao instituído pelos serviços de saúde mental, mas na busca por saberes-fazeres instituintes que potencializam a coprodução do cuidado.

Sua fala, portanto, apontava para o que nos diz Merhy (2019):

\begin{abstract}
se faz necessário o uso de tecnologias leves - presente no espaço relacional entre trabalhador-usuário e implicadas com a produção das relações entre dois sujeitos, que só tem existência em ato e não apenas as tecnologias leves-duras - expressas como que em uma caixa de conhecimentos técnicos do trabalhador e "na qual cabem saberes bem estruturados como a clínica ou a epidemiologia ou a pedagogia" - e nas tecnologias duras - expressas pela "caixa de ferramenta tecnológica" à disposição do trabalhador, ao alcance de suas mãos, como o aparelho de ECT, por exemplo - como a nota técnica pretende colocar. (MERHY, 2019: s/p)
\end{abstract}

Sobre o item "internação de crianças e adolescentes" nos mesmos espaços de pacientes adultos (quarto, enfermaria ou ala), o facilitador reflete sobre o destaque à "exceção" atribuída a esse fato no documento analisado. Explica a nota: "A melhor prática indica a necessidade de que tais internações ocorram em Enfermarias Especializadas em Infância e Adolescência. No entanto, exceções à regra podem ocorrer, sempre em benefício dos pacientes" (BRASIL, 2019). Destaca-se que a linha entre a "exceção à regra" e a "exceção como regra" é muito tênue, como aponta Agamben (2010), quando o estado de exceção representa o paradigma de governo.

Portanto, se estamos nos referindo aos modos de subjetivação que visam à construção de um corpo populacional dócil, submisso e subalternizado a um campo de saber-poder (médico), que vem renovando sua força autoritária na atualidade, esta se mostra uma estratégia salutar de produção de subjetividade adaptativa à sistêmica individualista-produtivista-capitalista-perversa. A infância e a adolescência são descaracterizadas como fase de desenvolvimento peculiar, como apontam alguns campos do conhecimento sobre desenvolvimento humano. Além dos prejuízos à produção de subjetividade de crianças e adolescentes expostas a 
tais modos de objetivação, observa-se aqui a negação do direito à cidadania de crianças e adolescentes de serem reconhecidos como tal. Passam por um processo de adultização da infância e adolescência por meio de práticas e concepções que remontam, de acordo com Ariès (1981), ao século XVI.

A partir das contribuições de Ariès (1981), apontamos que a infância é um acontecimento social e, portanto, está assentada em parâmetros sociais que em nosso contexto são sempre: ideológicos, políticos e econômicos. A partir da aquiescência adulta aos retrocessos nas políticas de atenção à saúde mental infantil e adolescente, podemos corroborar com a produção de subjetividades infantis adultizadas e adoecidas.

O leitor mais (des) atento deve estar questionando: o texto se refere "sempre em benefício do paciente". Aqui cabe questionar quais são os critérios e de onde estes advêm para determinar o que é o "benefício do paciente". Como determinálo? A partir de quais parâmetros? A estratégia discursiva da nota nos revela que não existem critérios, assim, na forma plural, apenas um critério, isto é, as determinações do discurso biomédico. Sabemos que este não é o único elemento a ser avaliado e considerado, senão a exceção (de internação mesmo junto a adultos) se torna a regra. Contudo, reconhecer outros campos do saber que tensionam esse saber-poder é desestabilizar o projeto político com qual ele está, historicamente, alinhado: a domesticação dos corpos-mentes a partir de estratégias autoritárias e higienistas.

Como nos esclarece Barros (2002: 73), o que nos interessa questionar a respeito do modelo biomédico mecanicista não se trata dos seus notáveis avanços a partir do século XVII conjuntamente com a física e a química, mas sim os "descaminhos ou as estratégias e interesses que, em especial a partir da revolução industrial capitalista passaram a prevalecer”. Nesse sentido, pode-se compreender que a biografia - compreendida como a narrativa e a enunciação da história do próprio sujeito e/ou grupo-sujeito - não importa quando se presume que a nosografia - a história da doença determinada por um agente externo (médico) - tornou-se o elemento verdadeiro para o trato com este corpo-sujeito (BARROS, 2002: 73-74).

O item "uso da abstinência no tratamento contra as drogas" aparece na nota técnica da seguinte forma: "Estratégias de tratamento terão como objetivo que o paciente fique e permaneça abstinente, livre das drogas" (BRASIL, 2019). Observa-se o apelo moral que o enunciado expressa ao relacionar a abstinência com a "liberdade" em relação às drogas. Para se ver livre delas, basta estar e permanecer abstinente. Tão simples quanto irresponsável, pois não se discutem quais os fatores implicados à dificuldade de se alcançar esse estado, nem sobre o saberpoder que regula essa obrigatoriedade. Além disso, responsabiliza-se unilateralmente o sujeito "usuário de álcool e outras drogas", uma vez que, caso não esteja abstinente, não será contemplado nas ações de "cuidado".

Essa proposta contraria a política de Redução de Danos, que pauta as estratégias de cuidado em saúde mental após a Reforma Psiquiátrica e a Luta Antimanicomial. Com base na política do Ministério da Saúde (2004-2003), o "Guia Estratégico para o Cuidado de Pessoas com Necessidades Relacionadas ao Consumo de Álcool e Outras Drogas: Guia AD” afirma:

RD é uma estratégia de saúde pública pautada no princípio da ética do cuidado, que visa diminuir as vulnerabilidades de risco social, individual e comunitário, decorrentes do uso, abuso e dependência de drogas. A abordagem da RD reconhece o usuário em suas singularidades e, mais do que isso, constrói com ele estratégias focando na defesa de sua vida. [...]. Uma das premissas da RD é que parte das pessoas que consomem algum tipo de drogas (lícita ou ilícita) não consegue, ou não quer, interromper o uso. 
Essa escolha não impede o direito ao cuidado e à saúde, conforme os princípios do SUS (Universalidade, Integralidade e Equidade). (BRASIL, 2015: 39)

Demonstra-se com isso a incompatibilidade da nota técnica intitulada "Nova Saúde Mental" com os princípios do SUS. Isto é, a novidade nada mais é que uma velha e arcaica repetição da estratégia biopolítica. Além disso, reafirma-se que a pretendida "política da abstinência" representa o retrocesso a um modelo higienista moralizante que vê um distúrbio moral no sujeito que apresenta uso nocivo de álcool e outras drogas.

O texto da nota traz em sua introdução um estudo que verifica "a migração considerável de doentes mentais graves para a população prisional”, isto é, a existência de "50.00o doentes mentais graves no cárcere". Segundo o estudo, "tal cenário é fruto direto dos equívocos fechamento de leitos psiquiátricos no Brasil, nas últimas duas décadas principalmente" (BRASIL, 2019). Isso evidencia a estratégia discursiva do documento que inicialmente apresenta uma pesquisa com dados alarmantes sobre a realidade dos grupos-sujeitos "portadores de algum transtorno mental" e, em seguida, justificam tal situação de maneira descontextualizada, correlacionando-a ao "fechamento de leitos psiquiátricos". Com isso, desconsidera de sua análise, enviesada por seus interesses controladores e autoritários, os inúmeros fatores que dificultam e inviabilizam até os dias atuais a implementação da política de saúde mental pensada a partir da Reforma Psiquiátrica e da Luta Antimanicomial.

Distorce também os reais motivos que ocasionam a situação apontada pela pesquisa, pois o encarceramento de pessoas em prisões não está associado à falta de leitos psiquiátricos, mas ao excesso do desejo de manicômios que insistem em habitar o imaginário social brasileiro e consequentemente a execução de suas políticas públicas. Afinal, a racionalidade moralista, higienista e policialesca permanece nas alternativas, aparentemente, contrapostas. Entre leitos e cárceres, existem sempre corpos-sujeitos impedidos de transitar-existir no mundo, como se a ele não pertencessem e cujas formas de vida precisassem ser continuamente interditadas, medicalizadas, "eletrificadas" (vide o recurso a ECT) e trancafiadas (vide a força do discurso hospital-psiquiatro-cêntrico).

O discurso da nota técnica n. 11/2019 visa, portanto, reintrojetar no imaginário social uma suposta necessidade de leitos psiquiátricos, como se as alternativas históricas a essa "política de leitos", como é o caso da "política do território" a partir dos avanços da reforma psiquiátrica, fossem responsáveis pelas dificuldades enfrentadas na execução das políticas de saúde mental na contemporaneidade. Isso fica evidente no desenrolar da "Oficina da Luta Antimanicomial" que será expressa na cena seguinte.

\section{CENA 3 \\ "É fácil falar do usuário, difícil é ser o usuário": as biopotências como antídoto às capturas biopolíticas}

A cena que se segue remonta novamente ao evento "Oficina da Luta Antimanicomial”, cuja fala começa a circular entre os demais presentes. Dentre as narrativas, destaca-se a de um ator-sujeito profissional de psicologia: "Não sei se é um problema incluir os hospitais na RAPS. Eu acho que precisamos sim de mais leitos hospitalares”. Em seguida, ele explica algumas situações reais em que identifica a necessidade de internação de alguns "usuários de álcool e outras drogas", mas que, supostamente, segundo seu discurso, devido à inexistência de leitos hospitalares se vê impossibilitado de realizar o cuidado desses usuários do serviço. 
Como a fala circula, alguns outros atores-sujeitos se manifestam em relação à opinião colocada. Uma profissional de psicologia destaca:

Concordo com a necessidade de auxílio de outros pontos da rede. Mas penso que isso não justifica a inclusão dos hospitais na RAPS. A própria RAPS tem a alternativa que é o CAPS III. O município já responde a esses critérios, só que fica apenas na promessa e nunca acontece [A implementação do CAPSad III].

Nessas narrativas percebemos os efeitos das relações de poder e de resistência. "Capturado" pela "racionalidade específica da responsabilidade profissional individual" diante do cuidado em saúde, o ator-sujeito se vê acuado diante da biopolítica que apresenta como alternativa a inclusão do hospital psiquiátrico na RAPS. Acuado, posto que a soma entre os dados de realidade (usuários com necessidade de outras estratégias de cuidado para além dos realizados no território existencial) mais a inoperância do Estado e suas formas de governo em relação à aplicação das políticas públicas (como a implementação do CAPSad III), faz com que o ator-sujeito se "renda". Com isso, ao perceber sua insuficiência diante da problemática, o trabalhador de saúde, desamparado, compreende que a única forma de cuidar do usuário é, aceitar a reação do biopoder. Desse modo, passa a concordar com o retorno da lógica manicomial hospitalocêntrica a partir da inclusão do hospital psiquiátrico na RAPS. Isso, em detrimento dos espaços de liberdade ou biopotência, criado pelo cuidado no território a partir da RAPS.

Em contraposição, a narrativa seguinte demonstra a necessidade de se analisar essa 'racionalidade específica da responsabilidade profissional individual' para "compreender como fomos capturados em nossa própria história" (FOUCAULT, 1995: 234). Portanto, "o que necessitamos é de uma nova economia das relações de poder - entendendo-se economia num sentido teórico e prático" (idem: 233).

Essa nova economia das relações de poder deve estar relacionada à situação presente, deve ser mais empírica.

\footnotetext{
Ela consiste em utilizar as formas de resistência contra as diferentes formas de poder como um ponto de partida. Para usar uma outra metáfora, ela consiste em usar essa resistência como um catalisador químico de modo a esclarecer as relações de poder, localizar sua posição, descobrir seu ponto de aplicação e os métodos utilizados. Mais do que analisar o poder do ponto de vista de sua racionalidade interna, ela consiste em analisar as relações de poder através do antagonismo das estratégias. (FOUCAULT, 1995: 234)
}

Na esteira das relações de poder e resistência, surge a fala de uma profissional de saúde ao ponderar sobre a noção de autonomia: "eu não sei se algumas pessoas têm condições de saber e escolher o que querem". Trata-se de uma narrativa reveladora de nossa produção de subjetividade pautada na cega devoção a uma suposta razão infalível de alguns (trabalhadores de saúde) e no seu desprovimento por parte de outros (usuário de álcool e outras drogas). Segundo a lógica de tal devoção, o usuário torna-se incapaz de responder por si mesmo e de assumir os rumos de sua vida, permanecendo em dependência total do poder-saber das disciplinas de saúde. Sobretudo do saber-poder biomédico, pois é quem detém as tecnologias de contenção.

No mesmo espaço de produção e na contramão dessa afirmação, ao nosso ver, encontra-se a enunciação do próprio usuário dos serviços: “É fácil falar do usuário, difícil é ser o usuário". Não basta que enunciemos sobre o outro ou sobre seu modo de levar a vida a partir das teorias e perspectivas científicas que possuímos. É preciso desfazermo-nos de nossas certezas sobre o outro, "usuário de álcool e 
outras drogas" ou "portador de transtorno mental”, para que possamos nos aproximar de seus devires.

Em outras palavras, é compreender, como nos aponta Emerson Merhy (2019: $\mathrm{s} / \mathrm{p}$ ), que "o cuidado é um acontecimento produtivo intercessor" que ocorre por um processo de intersecção partilhada e não por uma intersecção objetal. Assim, na relação entre o trabalhador de saúde e os usuários, no jogo de necessidades que os acompanha, está presente uma relação entre o agente produtor (trabalhador) e o consumidor objeto da ação (usuário). Contudo, este não deixa de ser um agente ativo dessa relação em ato e que deve expressar seu modo de vivenciar e construir suas necessidades de saúde a partir de sua intencionalidade, representações e conhecimentos. Nesse processo de trabalho, tem-se a possibilidade de se perspectivar a realização de um produto final, que pode ser a saúde do usuário caso seja compreendida por este como um facilitador que o permita viver a vida no mundo de acordo com seu universo de representações.

Ademais, alerta-nos Merhy (2019) sobre as necessidades que os agentes consumidores e produtores portam, macro e micropoliticamente. No entanto, além de as possuírem, eles também instituem necessidades singulares, que na relação entre trabalho vivo e trabalho morto ao qual estão submetidos, atravessam e desestabilizam o modelo instituído.

\section{(In) Conclusões finais}

A partir de tudo o que foi discutido, e inspirando-nos em Peter Pal Pelbart (2015: 25), indagamos: "Seriam as virtualidades do desejo sempre esmagadas por uma megamáquina social?" Quisemos, durante este longo percurso etnográficoanalítico, problematizar os dilemas, os limites e as possibilidades das políticas de saúde mental. Ao destrincharmos a "Política do Ministério da Saúde para Atenção Integral a Usuários de Álcool e outras Drogas" (BRASIL, 2003) e a nota técnica n. 11/2019 (BRASIL, 2019), buscamos compreender as nuances que cercam dispositivos de saber-poder contemporâneos e tomá-los como um campo em disputas.

Se a política de 2003, em vários momentos, resvalou em uma compreensão moralizante do usuário, ao mesmo tempo representou um grande avanço nos modos de intervenção nas políticas antidrogas (com o claro investimento no modelo da redução de danos). A nota técnica de 2019, por outro lado, resultou em um verdadeiro retrocesso. Assim, por meio da inclusão de hospitais psiquiátricos nas Redes de Atenção Psicossocial (Raps), do incentivo ao uso da eletroconvulsoterapia (ECT), da internação de crianças e adolescentes e do uso da abstinência no tratamento contra as drogas, o que se revela no documento é uma concepção de saúde medicalizante e uma prática interventiva policialesca, arbitrária e autoritária.

Ademais, ao pensarmos tais modelos de políticas em termos de descontinuidades, continuidades e retrocessos, quisemos explicitar sua dimensão não predeterminada e sempre aberta a disputas, agenciamentos e resistências. Assim, buscamos fugir de uma perspectiva binária e maniqueísta, ilustrada por uma política de "ou uma coisa ou outra”. Pelo contrário, ao percorrer a política e os territórios produzidos por ela e em torno dela, deparamo-nos com sujeitos, coletivos e narrativas que apontavam para a potência de devires dissidentes e resistentes discursivos e existenciais que, apesar de aparentemente interditos e capturados, ousavam (e ousam) mostrar que a loucura [ousaríamos afirmar: o vício] não é algo que deve ser interditado ou enclausurado, mas simplesmente vivido. Afinal, 
Quando há um acontecimento em que se reintroduz essa dimensão [do imponderável], a do "tudo é possível", algo aconteceu, quebrou-se a continuidade do tempo histórico. É a força que Nietzsche (1987) chamou de intempestiva. Agenciamentos de desejo que fazem saltar pelos ares muita coisa, muitas das coisas que nos envenenam a vida. (PELBART, 2015: 25)

Portanto, assim como muitos de nossos interlocutores, buscamos desestabilizar a ordem discursiva da racionalidade cientificista na qual estamos inscritos (FOUCAULT, 2012), uma vez que percebemos em sua vontade de verdade a anulação de grupos-sujeitos e, consequentemente, suas potencialidades e formas de vida. Uma anulação e um desperdício justificados pela julgada incapacidade deste outro (usuário de álcool e outras drogas; portador de transtorno mental) de ser e de estar no mundo e da supremacia do saber-poder cientificista que, unilateralmente, pretende determiná-lo.

Sabemos que, para esse tipo de ciência biomédica positivista, hegemônica na construção da ordem discursiva, podemos ser vistos como algum tipo de monstro. Isso por que ela entende o autoritarismo e o controle sobre o corpo do outro, como expressões de cuidado e benevolência. Contudo, como aponta Foucault (2012), não seremos qualquer tipo de monstro, seremos "monstros verdadeiros", isto é, falamos-fazemos a verdade junto aos atores envolvidos, respeitando sua processualidade mesmo sem estar "no verdadeiro" da polícia discursiva da biopolítica, pois não desejamos repetir seus "erros disciplinados". Assim, buscamos a coprodução de processos de cuidado em saúde, um saber-fazer-com-saúdes e, desse modo, reverberamos as biopotências e as resistências por novas superfícies de registro: por uma sociedade sem manicômios.

\section{Recebido em 28 de agosto de 2019.} Aprovado em 3 de janeiro de 2020.

\section{Referências}

AGAMBEN, Giorgio. Homo Sacer: o poder soberano e a vida nua. Belo Horizonte: UFMG, 2010.

ARIÈS, Philippe. História social da criança e da família. 2. ed. Rio de Janeiro: Editora Guanabara, 1981.

BARROS, José Augusto C. Pensando o processo saúde doença: a que responde o modelo biomédico? Saúde e Sociedade, 11 (1): 67-84, 2002.

BARROSO, Priscila F.; KNAUTH, Daniela R.; MACHADO, Paula S. “Desintoxicação, medicamentos e reinserção social: o tratamento de usuários de crack em diferentes perspectivas”. In: FERREIRA, Jaqueline; FLEISCHER, Soraya (orgs.). Etnografias em serviços de saúde. Rio de Janeiro: Garamond, 2014.

BELUZI, Jacson Renato. “A cama é nossa casa”: uma análise antropológica sobre o encarceramento feminino de/para mulheres em uma instituição prisional no 
estado de Mato Grosso do Sul. Dissertação de Mestrado. Programa da Pós-Graduação em Antropologia Sociocultural. Dourados: Universidade Federal da Grande Dourados, 2019.

BRASIL. Lei n ${ }^{0}$ 10.216, de 6 de abril de 2001: dispõe sobre a proteção e os direitos das pessoas portadoras de transtornos mentais e redireciona o modelo assistencial em saúde mental. Diário Oficial da União, 09 Abr 2001. p. 2.

BRASIL. Ministério da Saúde. Secretaria Executiva. Coordenação Nacional de DST/Aids. A Política do Ministério da Saúde para atenção integral a usuários de álcool e outras drogas / Ministério da Saúde, Secretaria Executiva, Coordenação Nacional de DST e Aids. - Brasília: Ministério da Saúde, 2003.

BRASIL. Ministério da Saúde. Secretaria de Atenção à Saúde. Departamento de Ações Programáticas Estratégicas. Guia estratégico para o cuidado de pessoas com necessidades relacionadas ao consumo de álcool e outras drogas: Guia AD. Brasília : Ministério da Saúde, 2015.

BRASIL. Ministério da Saúde. Secretaria de Atenção à Saúde. Departamento de Ações Programáticas Estratégicas. Coordenação-Geral de Saúde Mental, Álcool e Outras Drogas. NOTA TÉCNICA No 11/2019-CGMAD/DAPES/SAS/MS. Brasília: Ministério da Saúde, 2019. Disponível em: http://pbpd.org.br/wp-content/uploads/2019/02/0656ad6e.pdf

BRIGAGÃO, Jaqueline; NASCIMENTO, Vanda Lúcia Vitoriano do; SPINK, Peter Kevin. As interfaces entre psicologia e políticas públicas e a configuração de novos espaços de atuação. REU (Sorocaba), 37 (1): 199-215, 2011.

DELEUZE, Gilles; PARNET, Claire. Diálogos. São Paulo: Editora Escuta, 1998.

FOUCAULT, Michel. A ordem do discurso: aula inaugural no Collège de France, pronunciada em 2 de dezembro de 1970. Tradução de Laura Fraga de Almeida Sampaio. São Paulo: Edições Loyola, 2012.

FOUCAULT, Michel. História da Sexualidade 1: a vontade de saber. Rio de Janeiro: Edições Graal, 1988.

FOUCAULT, Michel. “Governamentalidade”. In: MACHADO, Roberto (org.). Microfísica do Poder. 26 ed. São Paulo: Graal, 2007. pp. 277-293.

FOUCAULT, Michel. "O sujeito e o poder". In: RABINOW, Paul; DREYFUS, Hubert. Uma trajetória filosófica: Para além do estruturalismo e da hermenêutica. Rio de Janeiro: Forense Universitária, 1995. pp. 231-249.

GODOI, Rafael. Fluxos em cadeia: as prisões em São Paulo na virada dos tempos. Tese (Doutorado em Sociologia), Universidade de São Paulo, 2015.

GUATARRI, Félix. Revolução molecular: pulsações do desejo. $3^{\text {a }}$ ed. São Paulo: Editora Brasiliense, 1985.

LUCHMANN, Lígia Helena Hahn; RODRIGUES, Jefferson. O movimento antimanicomial no Brasil. Ciência e Saúde Coletiva, 12 (2): 399-407, 2007.

MERHY, Emerson Elias. O cuidado é um acontecimento e não um ato. [Internet]. [s.d.]. [acesso em 2019 ago 21]. Disponível em: http://eps.otics.org/material/entrada-outras-ofertas/artigos/o-cuidado-e-acontecimento-e-nao-umato/view

MACHADO, Ana Regina. MIRANDA, Paulo Sérgio Carneiro. Fragmentos da história da atenção à saúde para usuários de álcool e outras drogas no Brasil: da 
Justiça à Saúde Pública. História, Ciências, Saúde - Manguinhos, 14 (3): 801821, 2007.

PELBART, Peter Pal. Políticas da vida, produção do comum e a vida em jogo... Saúde e Sociedade, 24 (1): 19-26, 2015.

RUI, Taniele. Nas tramas do crack: etnografia da abjeção. São Paulo: Terceiro Nome, 2014.

SANTOS, Francéli Francki dos; FERLA, Alcindo Antônio. Saúde mental e atenção básica no cuidado aos usuários de álcool e outras drogas. Interface, 21 (63): 83344, 2017.

TENÓRIO, Fernando. A reforma psiquiátrica brasileira, da década de 1980 aos dias atuais: história e conceito. História, Ciências, Saúde - Manguinhos, 9 (1): 25-59, 2002. 